\title{
Impact of different silkworm dietary supplements on its silk performance
}

\author{
Daniel Nicodemo $\cdot$ Juliano E. Oliveira $\cdot$ \\ Anderson Aparecido Sedano · José Manoel Marconcini • \\ Gustavo H. D. Tonoli
}

Received: 22 January 2014/ Accepted: 24 May 2014/Published online: 13 June 2014

(C) Springer Science+Business Media New York 2014

\begin{abstract}
This study aims to evaluate the effect of silkworm larva (Bombyx mori) diet supplementation with two amino acids (threonine and valine) on the cocoon production and on the structural and mechanical properties of the silk produced. Negligible morphological differences were observed in the silk fiber threads from silkworm larvae supplemented with the tested amino acids. Higher production (yield) of silk was obtained using threonine in the diet of the silkworm. The treatments with threonine have increased the limit of proportionality, tensile strength, toughness, and maximum deformation of the thread of silk fibers. No significant increment in these properties was observed due to the increase in the threonine content. The
\end{abstract}

D. Nicodemo - A. A. Sedano

Universidade Estadual Paulista, Campus de Dracena, Rod.

Comandante João Ribeiro de Barros, Km 651,

CEP 17900-000 Dracena, SP, Brazil

e-mail: nicodemo@dracena.unesp.br

A. A. Sedano

e-mail: andersonsedano@hotmail.com

\section{J. E. Oliveira}

Departamento de Engenharia de Materiais, Universidade Federal da Paraíba, Campus I, Centro de Tecnologia,

CEP 58051-900 João Pessoa, PB, Brazil

e-mail: juliano.materiais@gmail.com

J. M. Marconcini

Laboratório Nacional de Nanotecnologia para o Agronegócio (LNNA), Embrapa Instrumentação (CNPDIA), Caixa Postal 741, CEP 13560-970 São Carlos, SP, Brazil

e-mail: jose.marconcini@embrapa.br

G. H. D. Tonoli $(\bowtie)$

Departamento de Ciências Florestais, Universidade Federal de Lavras, Câmpus Universitário, Caixa Postal 3037,

CEP 37200-000 Lavras, MG, Brazil

e-mail: gustavotonoli@yahoo.com.br treatments with valine led to lower increase in tensile strength and toughness. The real density of the silk has decreased with the use of supplements. The present study contributes to engineering of advanced silk materials, which should be attractive candidates for multipurpose applications.

\section{Introduction}

Several domestic and wild insects are capable of producing silk through its specialized glands. According to Zhou et al. [1], the silk production is a mechanism for the protection of the developing larva from mechanical damages, wet environments, or predators. The silkworm cocoon silk fiber is composed of two cores of fibroin surrounded by a cementing layer of sericin in a structure known as a bave (each individual fibroin core is known as a brin) [2]. Silk fibroin is a semicrystalline polymer [3] of a natural fibrous protein mainly consisting of two important phases: (1) One is well known by the highly $\beta$-sheet crystals [4]; (2) the other is a non-crystalline form consisting of microvoids and amorphous structures [5], whereas sericin is amorphous and acts as an adhesive binder to maintain the fine filaments of fibroin core and the overall structural integrity of the cocoon [6]. Fibroin is the structural protein of the silk fiber, whereas sericin is the water-soluble proteinaceous glue that works bonding the fibers together [7]. The silk fiber is composed of fibroin (70-80\%), sericin (19-27\%), fats and waxes $(0.5 \%)$, and carbohydrates (1-1.5\%). The cocoons shells correspond up to $25 \%$ of total weight, while the insect pupae and the spoil represent 75 and $0.6 \%$ of the cocoon weight, respectively [8].

Silk is a material with interesting mechanical characteristics that make it unique. Its physical properties are not 
found in any other natural material. Moreover, silks have an interesting combination of extensibility and high tensile strength [9-11]. The silks spun by spider (Nephila clavipes) and silkworm (Bombyx mori) are similar when the chemical structure and chain of proteins are compared, but the silk produced by spiders is considered of higher quality because it has higher tensile strength and elasticity. However, the production of silk by spiders is in a very small scale in comparison with silkworm silk [11-14]. Teulé et al. [15] developed transgenic silkworms, encoding chimeric silkworm/spider silk proteins. Then, it was possible to obtain silk fibers tougher than the ones produced by ordinary silkworms.

Nowadays, silk fibers have been studied for the development of biomaterials for biomedical, and biotechnology industries [16-18] and the technologies must be improved in order to allow the production of high-value proteins from silkworms, considering their quality and economic viability $[19,20]$. Therefore, new and potential strategies in silk fiber spinning process are studied by several authors $[3,13,17$, 21]. Lucas et al. [22] and Reddy et al. [23] found that Attacus atlas silk is weak and with considerably different amino acids than those found in B. mori silk. Chen et al. [24] correlated mechanical properties with the structure and morphology of the cocoons, which appears to be more important than the differences in the properties of the silk fibers. Leclerc et al. [21] evaluated the effect of physicochemical environment ( $\mathrm{pH}$, salt concentration) on silk fiber production and properties. Several studies on properties of silk fibers have focused on the physicochemical modifications of the spinning process and suggest the control of fiber properties by dietary changes of the silkworm. Several authors found that protein composition plays a key role in mechanical properties of regenerated silk fibers $[25,26]$.

The silkworm producers provide only mulberry leaves (Morus alba L.) for the silkworms. Thus, the higher the yield and nutritional quality of the mulberry leaves, the greater the amount of silkworms to be reared, providing greater profitability for the cocoon producers [27]. Many factors may influence the silk production; among them, one of the most important is the percentage of protein content in the mulberry leaves. It is predicted that the dietary amount of protein on mulberry leaves is about $30 \%$ [28]. Whereas the quality of mulberry leaves does not always support the nutritional protein demand of the silkworm, because their lower protein percentages may lead to lower amount of cocoons, resulting in lower productivity [27].

The mulberry cultivars differ on the nutritional quality of the leaves, existing variations on chemical composition depending on the height of insertion of the leaf on the branch, the stage of plant development and management practices [29]. Factors such as the food intake, quality of the mulberry leaves provided, environmental conditions, and methods to allow the cocoon formation are the main factors affecting the quality of the cocoon [30].

Supplementing the diet of the silkworm with protein ingredients with high nutritional value and great digestibility may improve the development of the silkworms and cocoon production [31]. However, there is very few information available about artificial diets for silkworms due to low acceptance of the silkworm larvae for this way of feeding. Therefore, there is yet limited amount of information available on the variability of the properties of B. mori silk with different protein supplements, which may influence its overall properties and engineering applications. The limited amount of information available is most likely due to the fact that most of the information has been kept in house in the forms of industrial and agricultural reports and precisely is why this particular study is valuable. Thus, it is essential to conduct multidisciplinary researches that involve the evaluation of the larva growth based on nutritional enrichment of the mulberry leaves, focusing on the increment of cocoon production and improvement of the silk performance.

The income of the silkworm producer depends on the product quality, since price varies according to predetermined classifications. So the producer must meet the specifications and evaluation criteria in order to improve the cocoon quality.

The objective of this study was to evaluate whether the addition of threonine and valine in the diet of the silkworm larva interferes on the cocoon production and on the structural and mechanical properties of the ensuing silk.

\section{Experimental}

\section{Study area}

The experiment was done in the Faculty of Animal Science of UNESP, Campus of Dracena, which is located at: latitude $21^{\circ} 27^{\prime} 37^{\prime \prime} \mathrm{S}$ and longitude $51^{\circ} 33^{\prime} 21^{\prime \prime} \mathrm{O}$, and $421 \mathrm{~m}$ high. Mulberry (Morus alba L.) plants (FM86 variety) were used as the standard silkworm feed, in the fourth year of production, and cultivated in a $3.0 \times 1.0 \times 0.5 \mathrm{~m}$ nominal spacing. The harvest of the branches was performed daily in the early morning and in the late afternoon. After harvesting, the branches were stored in moistened plastic bags. Then, the silkworm rearing was held in a shed covered with white ceramic roof tiles, and the silkworm larvae remained in plywood beds measuring $50 \mathrm{~cm}$ high, $1 \mathrm{~m}$ wide $\times 3 \mathrm{~m}$ long.

\section{Silkworm dietary treatments}

The silkworm larvae were divided into five groups, with each group consisting of 700 larvae (Fig. 1). They were fed 
on mulberry leaves treated from the third to fifth instar, totaling 25 days, with four daily feeding times (from 7:30, $11: 30,15: 30$, and 19:30). Regarding the consumption of leaves, it was offered the same amount of leaves for the silkworm larvae, as suggested by Takahashi [32] and according to the larval stage.

Five diets were established based on the protein demand of the silkworm [30]. The diet 1 contained only mulberry leaves (control). The diets 2 and 3 were enriched with threonine, and the diets 4 and 5 were enriched with valine. Both threonine and valine are from commercial/analytical grade. To enrich the silkworm diet with amino acids, it was used a water-based solution sprayed on the leaves with manual sprayers. The amino acid concentration was of $1 \%$ (in relation to the protein demand of the silkworm) for diets 2 and 4 and of $2 \%$ (in relation to the protein demand of the silkworm) for diets 3 and 5. The daily amount of amino acids was equally divided between the feeding times of each instar.

After the feeding period, the larvae management was conducted for silkworm cocooning. The harvest of the cocoons occurred on the eighth day after the formation of the first cocoon (Fig. 1c), and the number of formed cocoons was used to determine the percentage of larvae mortality [mortality $=$ (number of larvae - number of cocoons)/ number of larvae * 100] from the third to fifth instar. All cocoons obtained were weighed, with the exception of the double cocoons. Then, the cocoons were cut for the removal of the insect pupae and spoil and weighed again in order to obtain the average weight of the cocoon shells.

For statistical analysis, it was used a completely randomized design with five diets. Means were compared by Tukey's test at $5 \%$ probability using the SAS program.

\section{Scanning electron microscopy (SEM)}

Each silk fiber thread is composed of around six individual silk fibers/baves (12 fibroin brins) obtained from six different silkworm cocoons, which are twisted into a thread after degumming in hot water. The threads of silk fibers were gold coated before been visualized in a LEO Evo40 XVP scanning electron microscope using secondary electrons (SE) mode. The thickness of the gold coating used here is typically around $20 \mathrm{~nm}$. The images were used to characterize the diameter, surface, and microstructure (e.g., the thickness of sericin layer) of the fiber threads.

\section{Mechanical characterization}

The silk fiber threads evaluated here consist of around six individual silk fibers (12 fibroin brins) bonded together. Around 10 silk fiber threads (which represent 60 individual silk fibers) were tested for each condition. The diameter of the silk fiber threads was carefully measured at four different positions using a digital micrometer ( $1 \mu \mathrm{m}$ resolution) and conducted according to well-defined prescriptions, following a $90^{\circ}$ rotation about the longitudinal axis of each silk fiber threads. Care was taken to avoid any damage to the fiber during measurement and whole experiment. The crosssectional area of the silk fiber threads was considered to have a circular shape, leading to a systematic error that probably sub estimate the tensile strength of the silk fiber threads in a lesser extent. Also, it was considered that the volume of the sample remains constant during the tensile test and is used consistently with previous work on B. mori silk [2, 3].
Fig. 1 a Silkworm feeding with mulberry valine-enriched leaves; b silkworm producing the silk cocoon; and c silk cocoons ready for harvesting

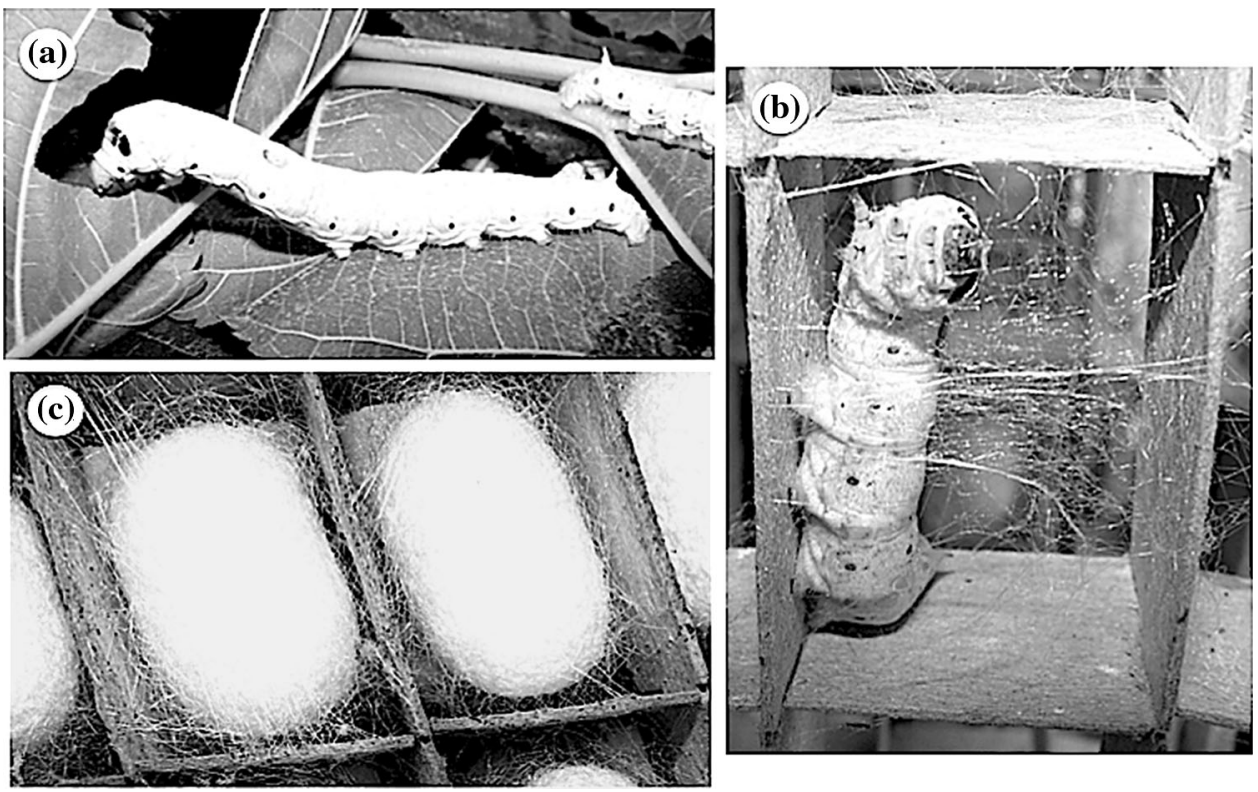


Mechanical tests were performed using the universal testing machine Emic DL-30000 equipped with $1 \mathrm{kN}$ load cell. A tensile configuration was employed to evaluate the limit of proportionality (LOP), tensile strength, toughness (T), modulus of elasticity (MOE), and maximum deformation of the threads of silk fibers. The first linear region of the stress versus strain curves was used to calculate MOE. LOP is the stress at the upper point of the linear portion of the stress versus strain curves, and tensile strength is the maximum stress detected. $\mathrm{T}$ is defined as the energy absorbed by the silk thread before rupture, which is calculated by integrating the area under the stress versus strain curves, divided by the cross-sectional area of the silk fiber threads, in order to achieve the uniform unit of the toughness (T) measured. The threads of silk fibers were tested dry (after $24 \mathrm{~h}$ at $50{ }^{\circ} \mathrm{C}$ ). Analysis of variance (ANOVA) was used to analyze the effects of the different amino acid treatments on mechanical properties of the silk fibers.

\section{Real density}

Real density of the threads of silk fibers was measured using a Quantachrome helium multipicnometer, model MVP-6DC.

\section{X-ray diffraction (XRD)}

For X-ray diffraction (XRD) measurements, silk fiber threads were wrapped on the top of the circular glass slides. XRD patterns were recorded using a XRD-6000 diffractometer (Shimadzu, Japan) with a Geiger counter connected to a computer. Scans were made in a $2 \theta$ scale from $5^{\circ}$ to $40^{\circ}$ at a speed of $0.07^{\circ} / \mathrm{min}$ using Ni-filtered $\mathrm{CuK} \alpha$ radiation. The full width at half-maximum height (FWHM) of the diffraction peaks were calculated by fitting the XRD data with a Gaussian-Lorentzian function.

\section{Infrared spectroscopy (FT-IR)}

The silk fiber threads were characterized in transmission mode in a Perkin Elmer Spectrum 1000 Spectrometer, in order to identify the eventual chemical changes obtained. All IR spectra were recorded at $2 \mathrm{~cm}^{-1}$ resolution using 64 scans.

\section{Thermogravimetry (TG/DTG)}

Silk fiber threads were subjected to thermogravimetric analysis (TG) in a TA Q500 thermal analyzer (TA Instruments, New Castle, DE, USA). The silk samples with around $12 \mathrm{mg}$ were heated in a Pt crucible from 25 to $600{ }^{\circ} \mathrm{C}$ in air flowing at $60 \mathrm{~mL} / \mathrm{min}$. The heating rate was $10{ }^{\circ} \mathrm{C} / \mathrm{min}$.

\section{Results and discussion}

\section{Cocoon production}

The larvae mortality ranged from 7 to $11 \%$ (Table 1 ) in the different treatments, whose values are similar to those obtained in commercial breeding [16]. The addition of valine in the higher concentration $(2 \%)$ seems to contribute to increase mortality of the larvae.

The heavier cocoons were obtained when using threonine, in the higher concentration (Table 1). There was no difference between the cocoons obtained when threonine was used at lower concentrations, when compared to control diet (only mulberry leaves). The addition of valine resulted in lighter cocoons than the control; however, the cause of this result was not yet elucidated. The effect of the addition of amino acids on the cocoons weight was similar to that obtained on the weight of the cocoons shells. The best results of production (yield) were verified when it was used the water solution with $2 \%$ threonine.

The addition of water-soluble soybean extract to the diet of the silkworm slight contributes to the quality of the cocoon. Besides, using this supplement, the most important result was the smaller amount of mulberry leaves necessary for equivalent production of cocoons, if no supplement is offered [30]. In the present work, the addition of threonine resulted in a significant improvement in the quality and yield of the cocoons, while the addition of valine influenced negatively the cocoons weight and cocoons shells weight.

The humidity of the mulberry leaves is the only water source for the silkworm. There is a large variation of the mulberry leaves depending on the cultivar, stage of plant development, harvesting period, storage time of the branches, temperature and humidity on the rearing environment, time of branches exposure on the rearing bed, height of the leaf in the plant, leaf thickness, and others [29, 33]. Horie and Watanabe [8] evaluated several diets with limiting amino acids. Based on that work, Hiramaya et al. [34] used a diet with $8.5 \%$ of total dry matter composed of essential amino acids. The supplement was composed of $17.6 \%$ of arginine, $5.3 \%$ of histidine, $9.5 \%$ of isoleucine, $16.4 \%$ of leucine, $11.8 \%$ of lysine, $3.5 \%$ of methionine, $10.2 \%$ of phenylalanine, $11.8 \%$ of threonine, $2.8 \%$ of tryptophan, and $11.1 \%$ of valine. That study showed that varying the content of amino acids is interesting on silkworm nutrition because it can promote significant differences on cocoon production.

\section{Morphological characteristics}

Coated with a residual sericin layer (arrows in Fig. 2), the silk fiber thread evaluated in the present work consists of 
Table 1 Larvae mortality (\%) from the third to fifth instar, and weight $(\mathrm{g})$ of the cocoons and cocoon shells of silkworm larvae fed with mulberry leaves enriched with threonine and valine at two levels

\begin{tabular}{lcll}
\hline Supplements & Mortality $(\%)$ & \multicolumn{2}{l}{ Weight $(\mathrm{g})$} \\
\cline { 3 - 4 } & & Cocoon & Cocoon shell \\
\hline Control & 7.71 & $1.61 \mathrm{~b}^{1}$ & $0.34 \mathrm{bc}$ \\
Threonine 1 \% & 8.29 & $1.66 \mathrm{ab}$ & $0.35 \mathrm{~b}$ \\
Threonine 2\% & 6.86 & $1.70 \mathrm{a}$ & $0.36 \mathrm{a}$ \\
Valine 1\% & 8.00 & $1.36 \mathrm{~d}$ & $0.28 \mathrm{~d}$ \\
Valine 2\% & 10.57 & $1.53 \mathrm{c}$ & $0.33 \mathrm{c}$
\end{tabular}

Means followed by the same letter in the column do not differ by Tukey's test $(5 \%)$

around six individual silk fibers (12 fibroin brins), which is obtained after degumming in hot water and combining multiple fibers from the cocoons into a thread. The structure of a silk fiber thread is shown in Fig. 2, where part of the sericin coating was removed during degumming in hot water. The average diameter of an individual silk fiber is of around $10 \mu \mathrm{m}$, including the sericin coating that is in the range of $1-2 \mu \mathrm{m}$ in thickness (arrows in Fig. 2).

As observed in Figs. 3, the cross section of the silk fiber threads is almost cylindrical and presents a diameter of around $60 \mu \mathrm{m}$. The individual silk fiber is formed by two fibroin brins with around $10 \mu \mathrm{m}$ diameter (each one), bonded together with sericin (Fig. 3d). Then, around 12 fibroin brins (or six individual silk fibers) can be observed in each silk fiber thread evaluated. The morphological characteristics agree with that reported in the literature where diameter of an individual silk fiber varies between 15 and $19 \mu \mathrm{m}$, including the sericin coating [35]. Khan et al. [7] reported values of silk fiber diameter in the range of $8-25 \mu \mathrm{m}$ for no degummed silk fibers. In general, the faster the spinning speed, the thinner the silk diameter. Also, there is a pronounced scatter in the silk diameter along its length, attributed to several reasons as reported by Zhao et al. [35]: (1) movement of the silkworm along the construction of the cocoon; (2) source of food (e.g., quality of the mulberry leaves) and health of the silkworm; and (3) measurement errors of the fiber diameter, since it is not perfectly circular in shape. Little morphological difference was observed in the silk threads from supplement with threonine and valine (Fig. 3b, c respectively). Valineenriched leaves seem to lead to decreasing of the bonding between the individual silk fibers produced.

\section{Mechanical performance}

The typical stress versus strain curves (Fig. 4) attained from a static tensile test of the silk fiber thread specimens are similar to that obtained for other elastoplastic materials with the so-called bi-elastic behavior. Typical stress versus

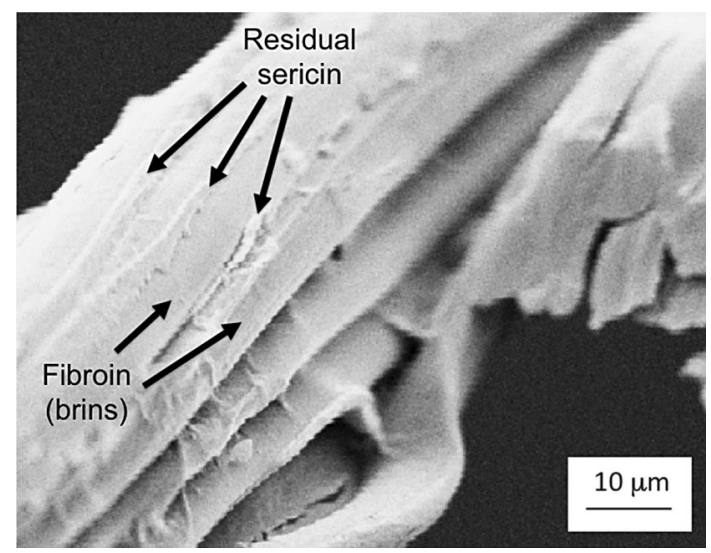

Fig. 2 SEM micrograph of the structure of the silk fiber thread. Arrows show the residual sericin coating that bonds the fibroin brins in a silk fiber thread

deflection curves mean that their profiles represent the average mechanical behavior of around 10 silk fiber threads (that represent the total of 60 silk fibers) subjected to a tensile test. The curves were chosen based on the average values of tensile strength and toughness (T), and the scattering of the data can be observed in the standard deviation values presented in Table 2. The stress versus strain curves can be separated roughly into an elastic region (1) and a plastic region (2). It was distinguished the two regimes by the clear deviation from the linear relation observed at the beginning of the tensile test (region 1). This first linear region (1) was used to calculate the MOE. Table 2 depicts the summary of the mechanical properties achieved with the silk fiber threads of the different treatments. The values are similar to those obtained elsewhere [7, 35-37]. No significant differences (at 0.05 level) were observed for the MOE and LOP values of the different treatments.

It was found that some silk samples of $B$. mori silk presented tensile strength of up to $0.93 \mathrm{GPa}$ and up to $34 \%$ of maximum deformation, which are comparable with the corresponding values of the dragline silk of Nephila sp. spiders, with $1.3 \mathrm{GPa}$ tensile strength and $40 \%$ maximum deformation [38]. The cross-sectional area of the silk fiber threads was considered to have a circular shape, which probably led to a systematic error with the sub estimation (in low extent) of their tensile strength in all treatments evaluated, due to the eventual voids between the silk fibers that compose the tested thread. Also, it is important to consider that silk fibers are twisted into a thread for this study, and then this will affect the tensile results as they will behave like a rope, leading to an overestimation of mechanical properties.

The treatments with threonine have increased significantly (at 0.05 level) the tensile strength, toughness (T), 

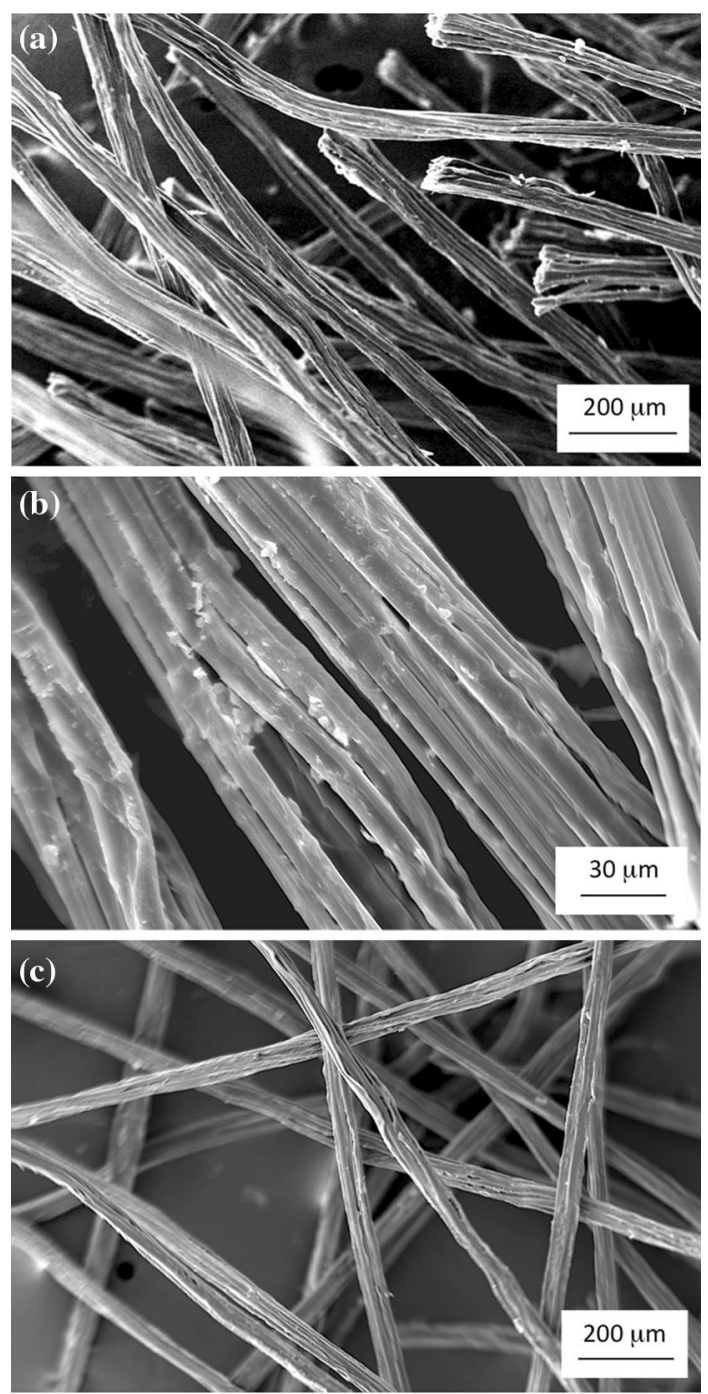

Fig. 3 SEM micrographs of the untreated (control) silk fiber threads (a); silk fiber threads obtained from threonine treatment (2\%) (b); and silk fiber threads from valine treatment $(2 \%)(\mathbf{c})$

and maximum deformation of the silk fiber threads. No significant increment in these properties was observed due to the increase in the threonine content. The treatments with valine led to no significant (at 0.05 level) increase in tensile strength and $\mathrm{T}$ values, in relation to the control (untreated leaves) samples. The maximum deformation was just higher for the treatment with $1 \%$ valine.

Table 2 also shows the results of real density of the silk samples. It is seen that mechanical properties increased with the decrease in the silk density. The treatment with threonine and valine seems to decrease the real density of the silk threads in relation to the reference (control) specimens, though the reason for this finding was not yet clarified. The results showed that the tensile properties of the silk fiber thread differ between the silkworm dietary supplements (mainly for threonine-enriched leaves), which

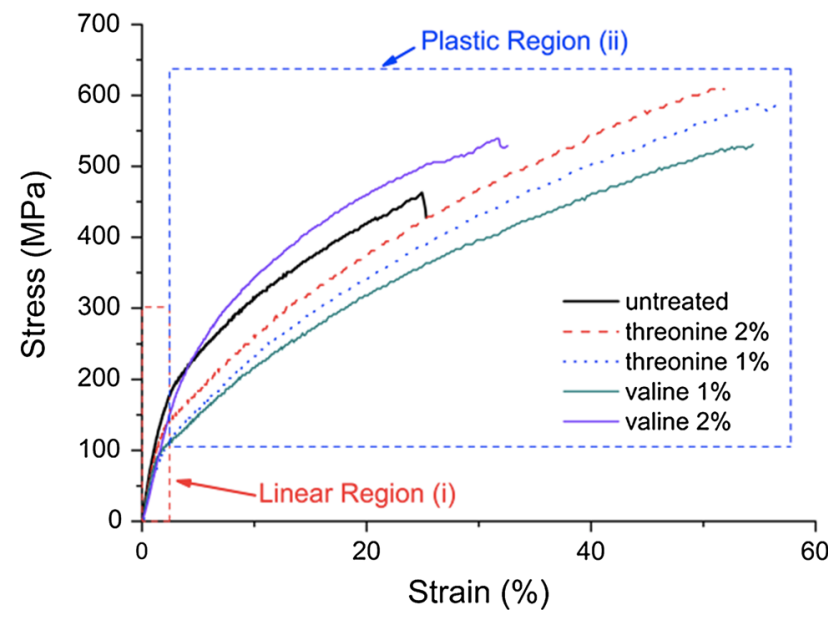

Fig. 4 Typical stress versus strain curves of the silk fiber threads in the different conditions

can be attributed to the changes in the chemical composition and structure of the silk fibers.

X-ray diffraction

The XRD patterns of the control (untreated) silk fibers and of those silk fibers from leaves treated with threonine and valine are shown in Fig. 5. The peak observed at $20.2^{\circ}$ corresponds to silk II structure ( $\beta$-sheet crystallinity) [39]; the peaks appearing at $\sim 10^{\circ}$ and $28^{\circ}$ have been also reported to be characteristic of silk fibers $[40,41]$.

The silkworm dietary supplement had no apparent effect on the crystallinity and XRD pattern of the silk fiber thread. The crystalline spacing, calculated by Bragg equation, of the silk fibers was $7.4\left(10^{\circ}\right), 4.4\left(20.2^{\circ}\right)$, and $3.2 \mathrm{~nm}$ $\left(27.9^{\circ}\right)$, and it corresponded to a lower d-spacing [42]. These XRD patterns are representative of a coexistence of an amorphous matrix with crystalline structure formed by $\beta$-sheets in the silk fibers. Crystalline $\beta$-sheets structure plays as a significant role in determining the physical and chemical properties of the silk fiber threads such as tensile strength, thermal behavior, and solubility [43].

\section{FT-IR results}

The FT-IR spectra of the silk fibers from different conditions were presented in Fig. 6 . Peak at $1230 \mathrm{~cm}^{-1}$ in silk fibers from leaves treated with $2 \%$ valine (Fig. 6a) was associated with the random-coil conformation [44]. Peaks at around 1525, 1639, and $1737 \mathrm{~cm}^{-1}$ (Fig. 6b) confirm the presence of the $\beta$-sheet structure ( $\beta$-sheet crystallinity) in silk fibers from untreated leaves and from leaves treated with $2 \%$ of valine or threonine, as observed elsewhere [45]. The peak at around $1639 \mathrm{~cm}^{-1}$ identifies the amide 
Table 2 Average values and standard deviation of the mechanical properties and real density of the silk fiber threads obtained from the different supplemental conditions

\begin{tabular}{lccccc}
\hline Properties & \multicolumn{1}{l}{ Treatments } & & \\
\cline { 2 - 6 } & Untreated & Threonine 1\% & Threonine 2\% & Valine 1\% & Valine 2\% \\
\hline LOP $(\mathrm{MPa})$ & $108.6 \pm 10.5$ & $119.0 \pm 11.5$ & $124.8 \pm 49.0$ & $106.0 \pm 23.5$ & $108.5 \pm 37.4$ \\
Tensile strength $(\mathrm{MPa})$ & $440.7 \pm 63.2$ & $609.4 \pm 55.5^{\mathrm{a}}$ & $613.7 \pm 210.2^{\mathrm{a}}$ & $524.1 \pm 75.5$ & $521.1 \pm 115.4$ \\
MOE $(\mathrm{GPa})$ & $71.8 \pm 8.9$ & $66.8 \pm 7.5$ & $74.6 \pm 21.3$ & $65.6 \pm 18.9$ & $68.1 \pm 15.4$ \\
T $\left(\mathrm{GJ} / \mathrm{m}^{2}\right)$ & $1.97 \pm 0.24$ & $4.35 \pm 0.12^{\mathrm{a}}$ & $4.09 \pm 1.70^{\mathrm{a}}$ & $4.09 \pm 1.32^{\mathrm{a}}$ & $2.22 \pm 0.53$ \\
Maximum deformation $(\%)$ & $17.6 \pm 5.5$ & $25.8 \pm 5.1^{\mathrm{a}}$ & $24.4 \pm 1.5^{\mathrm{a}}$ & $28.4 \pm 4.0^{\mathrm{a}}$ & $17.0 \pm 2.9$ \\
Real density $\left(\mathrm{g} / \mathrm{cm}^{3}\right)$ & $1.83 \pm 0.05^{\mathrm{a}}$ & $1.75 \pm 0.04$ & $1.74 \pm 0.05$ & $1.75 \pm 0.05$ & $1.75 \pm 0.02$ \\
\hline
\end{tabular}

$L O P$ limit of proportionality, $M O E$ modulus of elasticity, $T$ toughness

${ }^{a}$ Significant higher values (in the same line) at 0.005 level

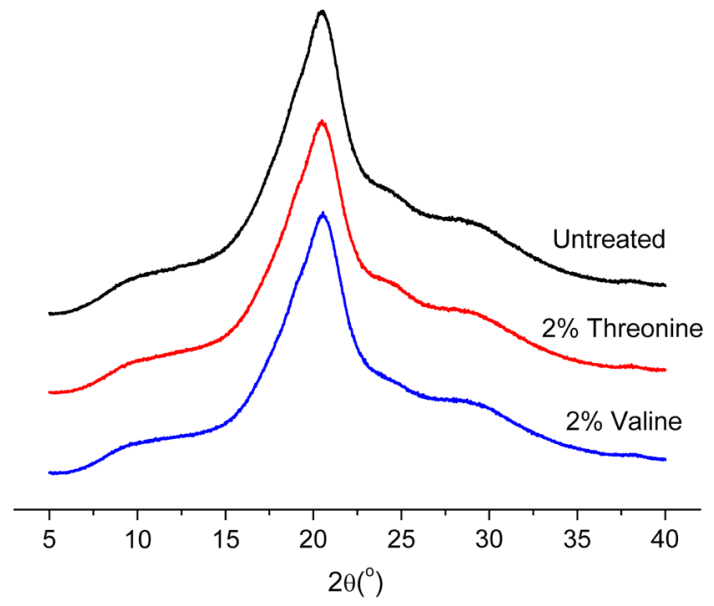

Fig. 5 X-ray diffraction patterns of the silk fibers from untreated leaves (control) and from leaves treated with threonine $(2 \%)$ and valine $(2 \%)$

groups (Fig. 6b). Silk fibers treated with $2 \%$ valine showed the characteristic peaks at $1221\left(\mathrm{CH}_{3}\right.$ stretching $)$, $1366\left(\mathrm{COO}^{-}\right.$bending), and $1596 \mathrm{~cm}^{-1}$ ( $\mathrm{COO}^{-}$stretching) [46], which were in higher intensities than in the control treatment.

\section{Thermal properties}

Figure 7 shows the thermogravimetric (TG) curves of the silk fiber threads from different supplemental conditions. The TG curves of silk fibers from untreated leaves and from treated leaves presented the same pattern. The TG curves (Fig. 7a) showed around $8 \%$ of weight loss at around $140{ }^{\circ} \mathrm{C}$ due to the dehydration of absorbed water in the silk fiber threads.

The obtained curves depict that decomposition in all samples of silk fiber threads occurred essentially in two stages; however, no important differences were observed
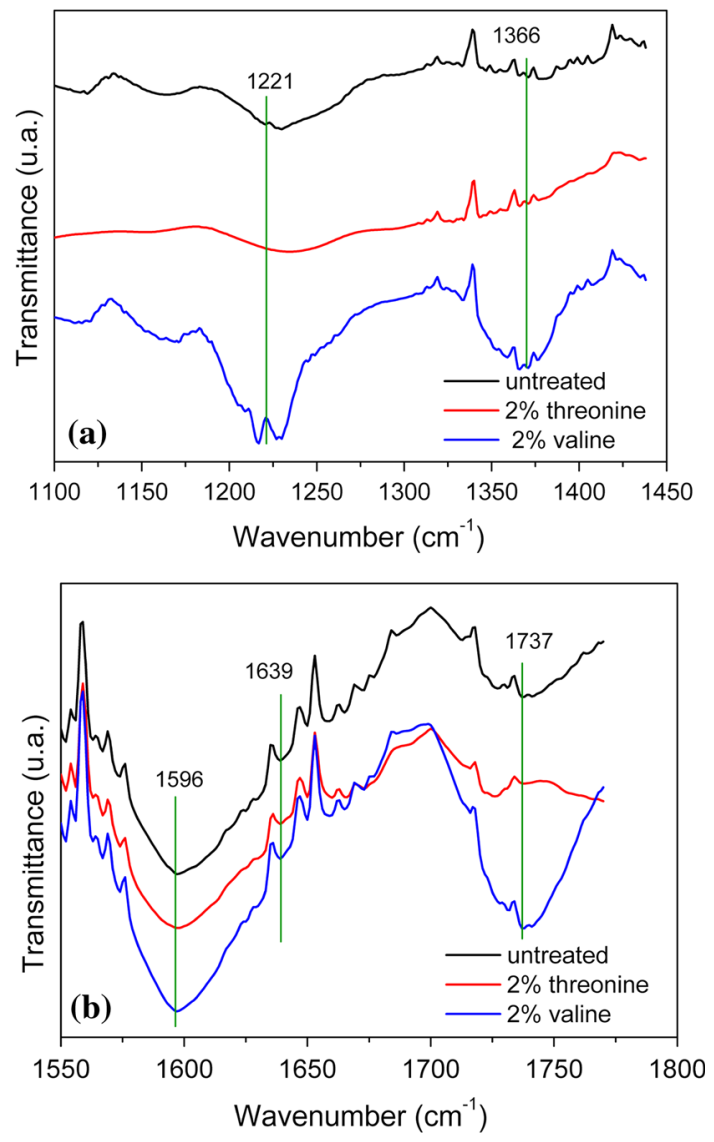

Fig. 6 FT-IR spectra of the silk fibers from different conditions. Region a $1100-1450 \mathrm{~cm}^{-1}$ and b $1550-1800 \mathrm{~cm}^{-1}$

between the silk compositions in the first stage. The first thermogravimetric (DTG) peak for all silk conditions was observed at around $300{ }^{\circ} \mathrm{C}$ (Fig. $7 \mathrm{~b}$ ), responsible for around $40 \%$ of the weight loss. The peak at $300{ }^{\circ} \mathrm{C}$ can be attributed to the degradation of low molecular weight species, resulting from the breakdown of side chain groups of amino acid residues. Also, it occurs from a broad endothermic transition ascribed to the thermal decomposition of 

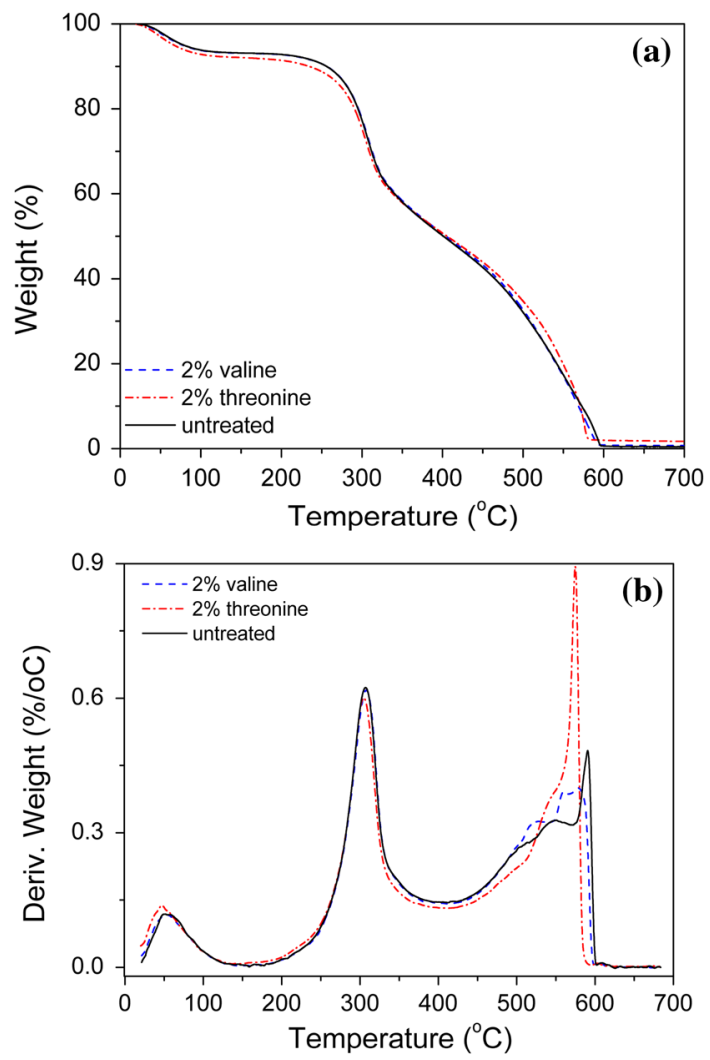

Fig. 7 TG (a) and DTG (b) curves of the silk fiber threads in the different conditions

silk fibers with oriented $\beta$-sheet crystalline structure [47]. The shoulder peaks at around 500 and $600{ }^{\circ} \mathrm{C}$ for all conditions are associated with the mass loss due to the decomposition of the fibroin molecules [39]. For the control sample (from untreated leaves), the decomposition of the fibroin occurred with the shoulder peak at around $500{ }^{\circ} \mathrm{C}$ and with the second one at around $550{ }^{\circ} \mathrm{C}$ (Fig. 7b). For silk fiber threads from treated leaves, the shoulder peak occurred at around $530{ }^{\circ} \mathrm{C}$ and the second peak occurred at around $570{ }^{\circ} \mathrm{C}$. Then, silk fiber threads from supplemental dietary with valine and threonine showed an increase in the temperature of degradation of the fibroin molecules in at least $20^{\circ} \mathrm{C}$. This increase in thermal stability is probably associated with changes in chemical and structural composition promoted by the dietary protein supplement.

\section{Conclusion}

Negligible morphological differences were observed in the silk fiber threads from supplements of threonine and valine. Higher production (yield) of silk was obtained using threonine in the diet of the silkworm. The treatments with threonine have increased significantly the tensile strength, toughness (T), and maximum deformation of the silk fiber threads. No significant increment in these properties was observed due to the increase in the threonine content. The treatments with valine have not led to significant increase in tensile strength and toughness, while the maximum deformation was just higher for the treatment with $1 \%$ (in relation to protein demand of the silkworm) of valine. No significant differences were observed for the MOE and limit of proportionality (LOP) of the different treatments. The real density of the silk has decreased with the use of supplements (threonine and valine). The present study enhances the understanding of the mechanical and structural properties of the silk and also is valuable for the design and engineering of advanced silk materials, which should be attractive candidates for biomedical, electrical, and textile applications.

Acknowledgements The authors thank Capes, CNPq, Embrapa Instrumentação, Fapemig, and Fapesp for their financial support.

\section{References}

1. Zhou L et al (2003) Copper in the silk formation process of Bombyx mori silkworm. FEBS Lett 554(3):337-341

2. Pérez-Rigueiro J et al (2000) Mechanical properties of single-brin silkworm silk. J Appl Polym Sci 75(10):1270-1277

3. Somashekarappa $\mathrm{H}$ et al (2002) Structure-property relation in varieties of acid dye processed silk fibers. Mater Lett 53(6):415-420

4. Takahashi Y, Gehoh M, Yuzuriha K (1991) Crystal structure of silk (Bombyx mori). J Polym Sci Part B Polym Phys 29(7):889-891

5. Robson RM (1999) Microvoids in Bombyx mori silk. An electron microscope study. Int J Biol Macromol 24(2-3):145-150

6. Jiang P et al (2006) Tensile behavior and morphology of differently degummed silkworm (Bombyx mori) cocoon silk fibres. Mater Lett 60(7):919-925

7. Khan MMR et al (2008) Structural characteristics and properties of Bombyx mori silk fiber obtained by different artificial forcibly silking speeds. Int J Biol Macromol 42(3):264-270

8. Horie Y, Watanabe K (1983) Daily utilization and consumption of dry matter in food by the silkworm. Bombyx mori (Lepidoptera: Bombycidae). Appl Entomol Zool 18(1):70-80

9. Chen F, Porter D, Vollrath F (2012) Silk cocoon (Bombyx mori): multi-layer structure and mechanical properties. Acta Biomater 8(7):2620-2627

10. Sirichaisit J et al (2003) Analysis of structure/property relationships in silkworm (Bombyx mori) and spider dragline (Nephila edulis) silks using Raman spectroscopy. Biomacromolecules 4(2):387-394

11. Gosline JM et al (1999) The mechanical design of spider silks: from fibroin sequence to mechanical function. J Exp Biol 202(23):3295-3303

12. Lewis RV (2006) Spider silk: ancient ideas for new biomaterials. Chem Rev 106(9):3762-3774

13. Scheibel T (2004) Spider silks: recombinant synthesis, assembly, spinning, and engineering of synthetic proteins. Microb Cell Fact $3(1): 14$

14. Hinman MB, Jones JA, Lewis RV (2000) Synthetic spider silk: a modular fiber. Trends Biotechnol 18(9):374-379

15. Teulé $F$ et al (2012) Silkworms transformed with chimeric silkworm/spider silk genes spin composite silk fibers with improved mechanical properties. Proc Natl Acad Sci 109(3):923-928 
16. Kameda T, Hashimoto T, Tamada Y (2011) Effects of supercooling and organic solvent on the formation of a silk sponge with porous 3-D structure, and its dynamical and structural characterization using solid-state NMR. J Mater Sci 46(24):7923-7930

17. Lawrence B et al (2008) Processing methods to control silk fibroin film biomaterial features. J Mater Sci 43(21):6967-6985

18. Zhang Y-C et al (2012) Conductive network formation during annealing of an oriented polyethylene-based composite. J Mater Sci 47(8):3713-3719

19. Hakimi $O$ et al (2007) Spider and mulberry silkworm silks as compatible biomaterials. Compos B Eng 38(3):324-337

20. Wurm FM (2003) Human therapeutic proteins from silkworms. Nat Biotech 21(1):34-35

21. Leclerc J et al (2013) Hydrodynamical properties of recombinant spider silk proteins: effects of $\mathrm{pH}$, salts and shear, and implications for the spinning process. Biopolymers 99(9):582-593

22. Lucas F, Shaw JTB, Smith SG (1960) Comparative studies of fibroins: I. The amino acid composition of various fibroins and its significance in relation to their crystal structure and taxonomy. J Mol Biol 2(6):339-349

23. Reddy N, Zhao Y, Yang Y (2013) Structure and properties of cocoons and silk fibers produced by attacus atlas. J Polym Environ 21(1):16-23

24. Chen F, Porter D, Vollrath F (2012) Structure and physical properties of silkworm cocoons. J R Soc Interface 9(74):2299-2308

25. Ki C, Park Y (2013) Effect of sericin blending on molecular orientation of regenerated silk fiber. Fibers Polym 14(9):1460-1467

26. Perea GB et al (2013) The variability and interdependence of spider viscid line tensile properties. J Exp Biol 216(Pt 24): 4722-4728

27. Takahashi R, Takahashi KM, Takahashi LS (2001) SericulturaUma Promissora Exploração Agropecuária. Funep. 140

28. Hamano K, Okano T (1989) Effect of dietary levels of protein and pyridoxine on growth of younger larvae of the silkworm, Bombyx mori. J Seric Sci Jpn 58(3):203-208

29. Okamoto F, Rodella RA (2004) Produção de casulos do bicho-daseda (Bombyx mori L.) e sua relação com características morfológicas e bromatológicas da folha de amoreira. Boletim da Indústria. Animal 6(2):91-99

30. Polycarpo GdV et al (2012) Enriquecimento da dieta do bicho-daseda com extrato hidrossolúvel de soja. Ciência Rural 42: 1669-1674

31. Ullal SR, Narasimhanna MN (1978) Handbook of practical sericulture. Central Silk Board, Meghdoot, Bombay, India, p 209
32. Takahashi, R, Takahashi KM, Takahashi LS (2009) Sericicultura: uma promissora exploração agropecuária, 2 ed. Jaboticabal: Funep, p 135

33. Porto AJ (2004) Perda de água em ramos de amoreira em função do cultivar e de técnicas de manejo alimentar. Boletim da Indústria Animal 61(1):49-56

34. Hirayama C, Konno K, Shinbo H (1996) Utilization of ammonia as a nitrogen source in the silkworm, Bombyx mori. J Insect Physiol 42(10):983-988

35. Zhao H-P, Feng X-Q, Shi H-J (2007) Variability in mechanical properties of Bombyx mori silk. Mater Sci Eng C 27(4):675-683

36. Mortimer B et al (2013) In situ tensile tests of single silk fibres in an environmental scanning electron microscope (ESEM). J Mater Sci 48(14):5055-5062

37. Yamauchi $\mathrm{K}$ et al (2010) Microscopic structural analysis of fractured silk fibers from Bombyx mori and Samia cynthia ricini using 13C CP/MAS NMR with a $1 \mathrm{~mm}$ microcoil MAS NMR probehead. Solid State Nucl Magn Reson 38(1):27-30

38. Shao Z, Vollrath F (2002) Materials: surprising strength of silkworm silk. Nature 418(6899):741

39. Mhuka V, Dube S, Nindi MM (2013) Chemical, structural and thermal properties of Gonometa postica silk fibroin, a potential biomaterial. Int J Biol Macromol 52:305-311

40. Khan MMR et al (2010) Physical properties and dyeability of silk fibers degummed with citric acid. Bioresour Technol 101(21): 8439-8445

41. Zarkoob S et al (2004) Structure and morphology of electrospun silk nanofibers. Polymer 45(11):3973-3977

42. Kweon H, Park YH (2001) Dissolution and characterization of regenerated Antheraea pernyi silk fibroin. J Appl Polym Sci 82(3):750-758

43. Humenik M, Scheibel T, Smith A (2011) Spider silk: understanding the structure-function relationship of a natural fiber. In: Stefan H (ed) Progress in molecular biology and translational science. Academic Press, New York, pp 131-185

44. Shao J et al (2005) Fourier transform Raman and Fourier transform infrared spectroscopy studies of silk fibroin. J Appl Polym Sci 96(6):1999-2004

45. Chen X et al (2001) Regenerated Bombyx silk solutions studied with rheometry and FTIR. Polymer 42(25):09969-09974

46. Ramachandran E, Natarajan S (2009) Synthesis of L-valine crystals. Cryst Res Technol 44(6):641-646

47. Ishikawa $H$ et al (1972) DSC thermograms of silk fibroin. Sen'i Gakkaishi 28(4-5):91-98 